\title{
Endoscopic Hemoclip Treatment for Bleeding Artificially Induced Mallory-Weiss Tears
}

Mallory-Weiss syndrome occurring as a result of diagnostic endoscopy has been described previously $[1,2]$. We report here on a case of severe iatrogenic Mallory-Weiss syndrome and treatment of the condition using Hemoclips.

A 62-year-old woman presented at an outpatient endoscopy department due to severe dysphagia. During the endoscopic examination, the instrument was advanced up to $32 \mathrm{~cm}$, at which point a button-like peptic stenosis was encountered that could not be passed. A 15-mm Rigiflex balloon was placed endoscopically and used to expand the stenosis. During maximum expansion of the stenosis, the patient developed a severe belching episode. The instrument was immediately withdrawn, and she then vomited bright red, foaming blood. A repeat endoscopy revealed two extensive longitudinal bleeding tears at the 4-o'clock and 8o'clock positions in a hernia (Figure $\mathbf{1}$ ).

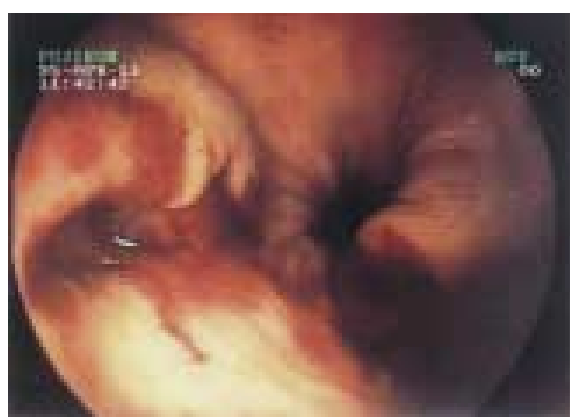

Figure 1 Extensive longitudinal and relatively broad bleeding tears in a hernia

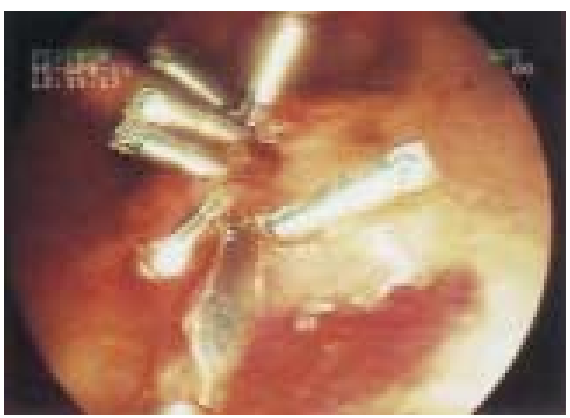

Figure 2 Complete closure of the wounds with Hemoclips
Hemoclip therapy [3 -5] was carried out to close the wounds endoscopically, due to the acute bleeding and broad wound dehiscence with a risk of perforation. A total of 12 Hemoclips were applied on the longer tear and five on the shorter tear (Figure 2). After complete closure of the mucosal defect, the bleeding stopped. Follow-up gastroscopies during the next 2 years only showed clips with surrounding hyperplastic tissue formation (Figure $\mathbf{3}$ ).

Bleeding caused by a mucosal tear can be stopped using endoscopic clipping, which closes the dehiscent wound. The danger of recurrent bleeding can be minimized by effective wound closure and compression of deeper blood vessels. Stabilization of the esophageal wall by closing the wound with Hemoclips can minimize the danger of perforation. The applied clips can remain in the esophagus, since healthy areas of esophageal mucosa are used to close the wound margins. Applying Hemoclips to bleeding tissue defects in the gastrointestinal tract is an effective, safe, and cost-effective method of stopping hemorrhage and preventing further complications.

\section{U. Will, T. Seidel, H. Bosseckert}

Dept. of Internal Medicine, University of Jena, Jena, Germany

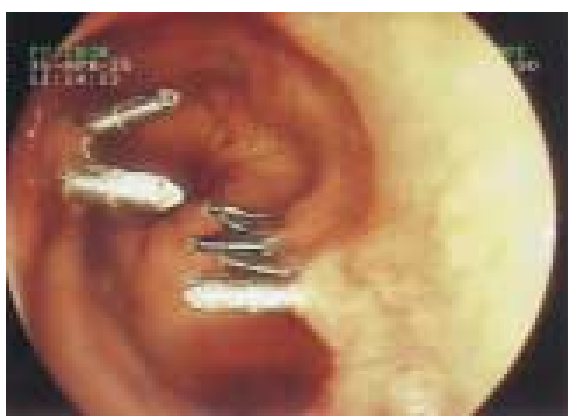

Figure 3 The remaining Hemoclips 1 year after treatment, with surrounding uninflamed polypoid hyperplastic tissue

\section{References}

${ }^{1}$ Sato H, Takase S, Takada A. The association of esophageal hiatus hernia with Mallory-Weiss syndrome. Gastroenterol Jpn 1989; 24: 233-238

${ }^{2}$ Reiertsen O, Skjoto J, Jacobsen CD, Rosseland AR. Complications of fiberoptic gastrointestinal endoscopy: five years' experience in a central hospital. Endoscopy 1987; 19: 1-6

${ }^{3}$ Binmoeller KF, Thonke F, Soehendra N. Endoscopic Hemoclip treatment for gastrointestinal bleeding. Endoscopy 1993; 25: $167-170$

${ }^{4}$ Scapa E. Treating gastrointestinal bleeding with endoscopic Hemoclips. Surg Laparosc Endosc 1997; 7: 94-96

${ }^{5}$ Yoshikane H. Hemostasis by capping bleeding diverticulum of the colon with clips. Endoscopy 1997; 29: S33

\section{Corresponding Author}

\section{U. Will, M.D.}

Dept. of Internal Medicine III

Straße des Friedens 122

07548 Gera

Germany

Fax: +49-365-828-2402

E-mail: uwe.will@ waldklinikumgera.de 